\title{
Do signo ao mito - uma análise semiológica das capas de revista Men's Health e G Magazine
}

\author{
The sign from the myth - a semiological analysis of magazine covers \\ Men's Health and G Magazine
}

\section{Rodrigo Fontanari}

Pontifícia Universidade Católica de São Paulo-PUC-SP - São Paulo - São Paulo - Brasil

Resumo:O objetivo deste artigo é elaborar uma leitura dos elementos verbovisuais presentes nas capas das revistas masculinas Men's Health e G Magazine a partir do modelo teórico proposto por Roland Barthes em seu livro Mitologias. Embora $G$ Magazine se destine a um público homossexual e Men's Health a um público heterossexual, nota-se uma estrutura bastante semelhante nas capas de tais publicações. Em ambas, aparece uma foto de homem com tipo físico atlético e com o torso despido, envolto por manchetes.

Palavras-chave:Semiologia. Roland Barthes. Mito.

Abstract:This work's main goal is to develop a reading of the verb-visual elements on the cover of the Brazilian male magazines Men's Health and G Magazine From the theoretical model proposed by Roland Barthes in his book Mythologies. Despite being the later directed to a homosexual public and the former to a heterosexual one, it's possible to note a rather similar structure on the cover of these publications. On both there's a picture of a well built athletic man displaying his naked thorax and surrounded by headlines.

Keywords: Semiology. Roland Barthes. Myth. 


\section{Roland Barthes e a semiologia}

O artigo propõe a abordagem das capas de revista Men's Health e G Magazine a partir do olhar de um dos expoentes da intelligentsia francesa do século XX, Roland Barthes. Como prefere apresentar a professora emérita da Universidade de São Paulo, Leyla Perrone-Moisés (cf. 2006), Barthes foi um crítico e teórico da literatura, do teatro, da cultura e da fotografia, mas também um semiólogo que se debruçou sobre vários objetos da cultura. Apesar de seus vários deslocamentos teóricos, é esse Barthes semiólogo, sobretudo, aquele do modelo sublime de desmontagem do discurso midiático proposto em seu Mitologias que nos interessa para a leitura das capas de revista.

Afinal, o que é semiologia? A semiologia é a ciência mais geral do signo, que tem como objeto de estudo todo sistema de signo, seja qual for a substância - as imagens (móveis ou estáticas), os gestos, os sons, os objetos, os ritos -, em suma, todos os sistemas de significação, aos quais o desenvolvimento das comunicações de massa propicia uma enorme difusão. Uma ciência ainda por ser edificada, quando, então, Saussure institucionaliza e edifica a linguística, que se torna o terreno caudaloso dessa "ciência por vir" (cf. BARTHES, CEuvresComplètes, II, 2002) ${ }^{1}$.

A semiologia estuda todo sistema de signos da vida social, enquanto que a linguística seria uma parte da semiologia que, por sua vez, seria parte da psicologia social. (SAUSSURE, 1978). Por ter como objeto de estudo apenas a linguagem verbal, a linguística é parte da semiologia que, por sua vez, se debruça sobre a significação de toda e qualquer linguagem. Enfim, a semiologia, como a sustenta Barthes, é uma ciência das formas, visto que estuda as significações independe do seu conteúdo.

Todo sistema semiológico sustenta-se numa subordinação geral ao sentido da linguagem articulada, do sentido da fala: a linguagem verbal

\footnotetext{
${ }^{1}$ As citações das obras de Roland Barthes foram extraídas das CEuvresComplètes, 5T, Nouvelle éditionrevue, corrigée et présentée par ÉricMarty. Paris: Seuil, 2002. Doravante mencionada sob forma abreviada OC
}

encontra-se em todos os níveis da análise dos sistemas não-verbais. Portanto, de certa maneira, a semiologia é uma extensão dos conceitos linguísticos de língua e fala. Assim, embora trabalhe de início com substâncias não-verbais, o semiólogo é chamado a encontrar, cedo ou tarde, a linguagem em seu caminho. Barthes, a contrapelo, inverte a proposição saussuriana e afirma que a linguagem não é uma parte, ainda que privilegiada, da ciência do signo, é a semiologia que é parte da linguística ou, mais precisamente, essa parte que se encarregou das grandes unidades do discurso (OC, II).

É somente em meados dos anos 1950 que a proposta saussuriana de uma semiologia passou a ser desenvolvida por pesquisadores europeus. 0 desenvolvimento dessa ciência, ainda que tardio em relação à primeira concepção proposta por Saussure, está vinculado, dentre outros motivos, à proliferação crescente dos meios de comunicação de massa, que criava a necessidade de uma ciência capaz de abarcar toda a natureza e as distinções entre variadas formas de linguagens veiculadas nos diferentes meios de comunicação. Para isso, era preciso um instrumental teórico que fosse capaz de desvendar a complexa natureza intersemiótica das artes. O campo semiológico está submetido ao modelo descoberto pela linguística. É a ciência que se debruça sobre os sistemas de signos da vida social. Numa compreensão mais ampla, é a apreensão de todo fato de cultura e de toda prática social como linguagem.

Cabe, a essa altura, uma ressalva: o século XX é notadamente marcado pelo apogeu do paradigma semiótico de cunho estruturalista na obra de Roland Barthes. Como aponta WinfriedNöth em A semiótica no século $X X$, os termos semiótico ou semiológico e o estruturalismo são tomados, praticamente, quase como sinônimos. Em 1963, Barthes, no capítulo "A atividade estruturalista", de seus Ensaios críticos, porá a palavra estruturalismo não como

[...] escola, nem mesmo um movimento (pelo menos, ainda não), pois muitos dos autores que costumeiramente são associados a essa palavra não se sentem minimamente vinculados por uma solidariedade de doutrina 
ou de combate. Trata-se apenas de um léxico. [...](OC,II, p. 466).

O termo estruturalismo assume, como nota François Dosse, "[...] o sentido da descrição da maneira como as partes integrantes de um ser concreto se organizam numa totalidade." (2007, p.24).

A semiologia barthesiana apresentada em Mitologias consiste numa excitação do olhar crítico. Essa excitação é uma desconstrução do mundo que nos rodeia, de tal forma que nele encontremos as funções-signos, isto é, um mundo signo dele mesmo. As funções-signos são, muitas vezes, objetos de uso sobre os quais a sociedade impôs fins de significação derivados pela finalidade de uso num determinado contexto social, ou seja, todo uso acaba por convergir em signo desse uso. São signos de origem utilitária e funcional. Cedo ou tarde, somos levados a encontrar, nos sistemas semiológicos, essas funções-signos que podem ser entendidas como um desvio de significação que o código constrói por meio da linguagem.

O projeto semiológico de Barthes está nessa fronteira entre o explícito e o implícito, o denotado e conotado (OC, I) do processo de comunicaçãosignificação. É a ciência de todas as significações e, estando as significações em todas as instâncias socioculturais, até mesmo nos objetos de uso, é a ciência da sociedade enquanto se significa e, ao mesmo tempo, se distorce, acenando que a semiologia barthesiana tenderia a tornar-se a ciência da ideologia ou uma ciência que teria a ideologia como último objeto de estudo. Muito mais do que uma busca pela denúncia do falsário no discurso, seu projeto se apresenta em meio à sua heterogeneidade de objetos e de métodos, um continuum maior que o olhar ácido sobre o signo. Como afirma François Dosse, em A história do estruturalismo, Barthes, com noção muito ampla de signo - tudo que se reveste de uma significação -, leva seus críticos em semiologia a afirmar que ele desviou o projeto original estabelecido por Saussure, de desenvolver uma semiologia da comunicação, para estabelecer uma simples semiologia da significação.
A semiologia se ocupa da descrição do funcionamento dos sistemas de comunicação nãolinguísticos. Na contracorrente, a semiologia da significação, que tem em Barthes seu representante ilustre, entende a língua e todos os fenômenos significativos como sistema de objetos de uso (função-signo), vendo nesses diversos segmentos, nas artes e na comunicação de massa, um fundo de linguagem impregnada de ideologia. Barthes busca nesses vários textos a tessitura do conteúdo latente (o sentido conotativo) da linguagem. Nas palavras do próprio Barthes

[...] a semiologia não é uma chave, ela não permite apreender diretamente o real, impondo-lhe um transparente geral que o tornaria inteligível; o real, ela busca antes soerguê-lo, em certos pontos e em certos momentos, e ela diz que esses efeitos de solevamento do real são possíveis sem chave: aliás é precisamente quando a semiologia quer ser uma chave que ela não desvenda coisa alguma. (OC, V, p. 442).

\section{Das Mitologias}

Roland Barthes, em Mitologias, editada em 1957, inaugura uma análise crítica da propaganda e do marketing na sociedade francesa da época. Sem dúvida, esse livro é um clássico cujos ensinamentos não conseguimos trocar por coisa melhor. Elabora uma verdadeira desmontagem, à vista armada da linguagem, e revela que os aparatos da comunicação de massa (a publicidade e o marketing), por meio de operações discursivas, tratam de naturalizar a cultura, fazendo passar suas palavras por inocentes.

Nos primeiros momentos dos anos de 1950, o projeto estruturalista vai se desenvolver e irradiar-se de tal forma que assume uma liberdade bastante considerável em relação à ortodoxia da escola. Barthes, a tal altura, visava a uma semiologia da comunicação para elaborar apenas uma semiologia da significação: "um olhar" sobre o mundo.

Por outro lado, é inegável que, nesse mesmo período, o autor encampou um projeto de escritura Mitologias - desmontando as camuflagens elaboradas pelos meios de comunicação, que fazem passar as palavras por inocentes, na medida em que 
naturalizam aquilo que é culturalmente construído. Esse livro representa o que os comentários de barthesianos convencionaram denominar de préteórico. Nesse período, ainda Barthes não havia se incorporado plenamente do projeto semiológico saussuriano. O que faz somente anos mais tarde, após um encontro, em Alexandria, com A. J. Greimas, que lhe apresenta o pensamento saussuriano. Aqui é importante que nos detenhamos com um pouco mais de apreço a esse livro que representou um ponto de virada na obra barthesiana e sinaliza seus pontos de deslocamentos e mergulhos científicos.

Mitologias nasce da reunião de cinquenta e quatro breves e fulgurantes textos, que são verdadeiras "mitologias do mês" sobre a sociedade francesa. Desse conjunto de textos, cinquenta e dois deles foram publicados em LesLettresNouvelles. Depois, na revista Critique, publicou-se "catch", de 1952. Já "O escritor de férias", de 1954, saiu na revista France-Observateur ${ }^{2}$. Todos eles escritos pelo autor entre 1952 e 1956.

Do título apresentado ao volume, somos levados, ironicamente, a um jogo de palavra. Ali o autor emprega a palavra "mito" deslocada da raiz etimológica grega - que significa "uma lenda, um relato simbólico da condição humana" - para empregá-la como uma mentira, uma mitificação. Trata-se de uma denúncia ao giro em falso dos produtos culturais que, por meio do uso abusivo da linguagem, ensaiam ser o que não são: verdadeiros produtos naturalmente constituídos.

Nesse sentido, Mitologias não é, senão, como adverte Louis-Jean Calvet, uma reação, uma denúncia contra "[...] a distorção ideológica, a tentativa de fazer passar como naturalidade o que de fato era profundamente cultural, ou de fazer inato o que na verdade era adquirido." (CALVET, 1993, p.

\footnotetext{
${ }^{2}$ LesLettresNouvelles é uma revista literária semanal francesa fundada em 1953 por Maurice Nadau e Maurice Saillet. Critique revista literária mensal criada em 1946 por George Baitelle. France-Observateur originou-se em 1950, do periódico L'Observateur politique sobre economia e literatura. Em 1953 passa a se chamar L'Observateuraujourd'hui e em 1954, muda para France-Observateur. Atualmente, chamada de Le NouvelObservateur, desde 1964 dedica-se às áreas de política, economia e cultura.
}

143). Mais precisamente, nas palavras do próprio Barthes:

[...] o ponto de partida desta reflexão era freqüentemente um sentimento de impaciência diante do 'natural' com o qual a imprensa, a arte, o senso comum encobrem sem cessar uma realidade que, por ser aquela na qual vivemos, não deixa de ser perfeitamente histórica.(OC, I, p. 673).

A publicação de Mitologias começa a ser então preparada no verão de 1956, mas Barthes ainda precisava encontrar uma justificativa que fizesse sentido para reunir em um único volume os cinqüenta e quatro textos publicados independentes uns dos outros. O que os vincula é a propagação recorrente do mito que se insere num código para que a burguesia possa transmitir sua ideologia. Para tanto, fazia-se necessário descrever esse sistema mitológico, o que levou a originar o posfácio "O mito hoje". Esse texto marca o mergulho barthesiano no mundo da semiologia, o que o impulsionou a passar esses textos de atualidade crítica aguda de "mitologias" para um crivo discursivo mais amplo e geral da "semiologia", tomando emprestado de Saussure e de Hjelmslev as nomenclaturas de signo, de denotação e conotação, respectivamente. Esse texto é uma aula barthesiana prática sobre o funcionamento das mitologias midiática. Como nos mostra Barthes, o mito desloca o signo de um contexto e o faz funcionar, como significante afetado de outro significado, em outro contexto que, por sua vez, assume outra significação de "segundo grau". Explicita Barthes,

[...] no mito existem dois sistemas semiológicos, um deles deslocado em relação ao outro: um sistema linguístico, a língua (ou os modos de representação que lhe são comparados), que chamarei de linguagemobjeto, porque é a linguagem de que o mito se serve para construir o seu próprio sistema; e o próprio mito, que chamarei de metalinguagem, porque é uma segunda língua, na qual se fala a primeira. (OC, I, p.829).

Admita-se: de longe toda essa construção do mito é uma prerrogativa que vale, em princípio, para a própria poesia. Como aponta Leda Tenório da Motta (cf.2003), em Literatura e contracomunicação, 
relembrando Roland Barthes, o mito é de saída tomado como "uma palavra", termo esse que, como já notamos, no limite, recobre a poesis grega (fazer). Assim, o mitólogo é um poeta que, se valendo da prerrogativa da linguagem e da técnica da poesia (da retórica), elabora uma "má poesia". Embora a palavra poética e a mítica se assumam como metalinguagem, isto é, sistemas semiológicos, na poesia, o que se tem é a saturação dos significantes de modo que o sentido, ainda que finito, permaneça suspenso, enquanto que, na mítica, sem maiores explicações, o mitólogo apropria-se dos significantes de uma linguagem primeira que Ihe é estranha, reduzindo-os a um único sentido.

O que meios de comunicação de massa, em sua maioria, produzem não são senão essa "má poesia", buscando passar a todo custo por natural aquilo que é culturalmente construído. Esse conjunto de textos de Mitologias pode ser lido como um discurso em que reverbera "eco de uma atualidade que funciona, ao mesmo tempo, como revelador de um olhar (...) e de um instinto analítico." (CALVET, 1993, p.146)

\section{0 mito: modelo de desmontagem}

Para a compreensão do modelo de desmontagem proposto por Roland Barthes em "O mito hoje", devemos recorrer ao Curso de lingüística geral de Saussure e ao Prolegômenos a uma teoria da linguagem de Hjelmslev. Tais obras são importantes para explicarmos alguns conceitos dos quais Barthes se utiliza para explicar o processo de desconstrução semiótica do mito. São eles: signo, significante, significado, significação de Saussure, e denotação e conotação de Hjelmsv.

O signo é, em termos saussurrianos, biplano composto por um significante (imagem acústica) e um significado (conceito). O signo seria então a relação entre essas duas grandezas, ou seja, sons ou sequências de sons e ou suas correspondências gráficas que estão laçados a conteúdos. Nesse sentido, o signo é um instrumento de comunicação e representação, com eles construímos linguisticamente a realidade e distinguimos os objetos entre si. O significante é um relatumque não pode se separar do significado. Sendo que o laço que une o significante ao significado é arbitrário. O significado, por sua vez, não é a coisa em si, mas uma representação psíquica dela. A significação deve ser entendida como processo que une o significante e o significado, cujo resultado é o signo. O próprio Barthes se encarregou de apresentar aos franceses toda essa filigrana em seus Elementos de semiologia (1965).

Recapitulemos, rapidamente, o funcionamento do mito para que possamos bem compreender 0 sentido do que Barthes denomina sistema mítico. Sabemos que o mito é, em termos semiológicos, um signo que comporta um significante e um significado. Barthes complexifica o sistema e adiciona um terceiro elemento a essa relação - o próprio signo construído a partir da relação entre o significado e o significante. No entanto, se o significante, no mito, é vazio, o signo é pleno, repleto de sentidos. Assim, "[...] no plano da análise, não posso confundir as rosas como significante e as rosas como signo: o significante é vazio, o signo pleno, é um sentido." (OC, II, p. 826). Como demonstra Barthes,

No mito, pode encontrar-se o mesmo esquema tridimensional de que acabei de falar: o significante, o significado e o signo. Mas o mito é um sistema particular,visto que ele se constrói a partir de uma cadeia semiológica que existe já antes dele: é um sistema semiológico segundo. O que é signo (isto é, totalidade associativa de um conceito e de uma imagem) no primeiro sistema, transforma-se em simples significante no segundo. É necessário recordar, neste ponto, que as matérias-primas da fala mítica (língua propriamente dita, fotografia, pintura, cartaz, rito, objeto etc.), por mais diferentes que sejam inicialmente, desde o momento em que são captadas pelo mito, reduzem-se a uma pura função significante: o mito vê nelas apenas uma mesma matéria-prima; a sua unidade provém do fato de serem todas reduzidas ao simples estatuto de linguagem.(OC, II, p.828).

Podemos ler o mito como um sistema em que há, em seu cerne, dois signos, "um signo de segundo grau". Segundo Barthes, 
O significante do mito apresenta-se de uma maneira ambígua: é simultaneamente sentido e forma, pleno de um lado, vazio de outro. Enquanto sentido, o significante postula já uma leitura, apreendo-o com os olhos, ele tem uma realidade sensorial (ao contrário do significante lingüístico, que é de ordem puramente psíquica), tem uma riqueza. (OC, II, p. 830).

O significante do signo é vazio de sentido, está em oposição aquele do mito em que seu sentido é dúbio. Sabemos que ele não é vazio como o significante, pois é signo num primeiro sistema e, por isso, pleno. Mas, quando transformado em mito, o significante, que já se encontra carregado de um primeiro sistema de sentido anterior, é esvaziado nesse segundo. A maneira pela qual o mito adquire sentido é da ordem do conceito. Assim, segundo Barthes, "Através do conceito, toda uma história nova é implantada no mito." (OC, II, p. 832). Em termos míticos, temos: como termo final do primeiro sistema denomina-se de o significante de sentido, no plano do mito denomina-se forma. O significado, nesse segundo sistema, chama-se conceito. O terceiro termo que, na língua, seria o signo, no sistema mítico, é a significação. De resto, fiquemos com o esquema de mito proposto por Barthes.

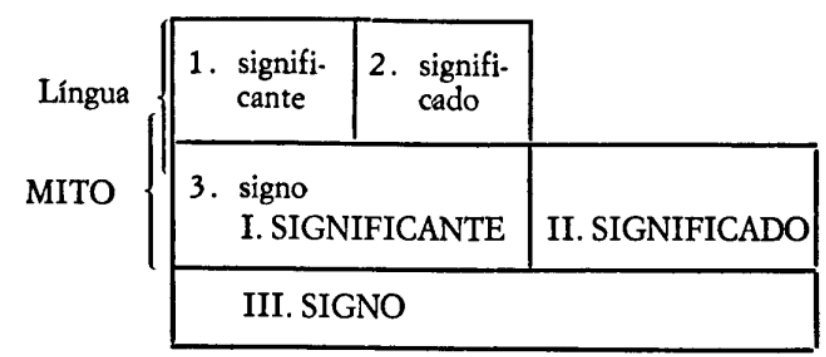

Figura 1: Roland Barthes. "Le mytheaujourd'hui”.OC, I, p. 828.

O mito tem como tarefa dar sentido a uma dada realidade, ou seja, explicar algo que, em princípio, aparece como estranho. Ele alça voos mais altos e invade várias instâncias da vida cotidiana, que vai, por exemplo, da luta livre - "Catch" -, passando pela fotografia, até o discurso midiático. Com sublinha Roland Barthes, "o mito é uma fala despolitizada" (OC, II, p. 855), mas que carrega em seu bojo toda uma construção ideológica.

Uma boa ilustração dessa linguagem retorcida e do processo de desmontagem mitológica é, como aponta Barthes, a capa do Paris-Match, em que um jovem negro portando uniforme francês faz saudação militar com os olhos erguidos, fixados a uma das pregas da bandeira tricolor (francesa). Esse é o sentido da imagem, ou seja, há um significante (sentido) formado por um sistema linguístico anterior (um soldado negro faz saudação militar francesa). $O$ mito esvazia, empobrece, afasta a história, o sentido, transforma-o em forma. Mas numa leitura não muito ingênua, percebemos o que essa forma significa, que a França é um grande Império e que todos os seus filhos, sem distinção de cor, servem fielmente a sua pátria e que não há melhor resposta para os que atacam o colonialismo do que a dedicação desse jovem negro servindo aos seus opressores. A forma do mito não é símbolo: o negro que saúda a bandeira francesa não é símbolo do Império Francês, porque é uma imagem demasiadamente evidente, mas ela ganha um significado no processo de significação, uma mistura intencional de "francidade" [francité] e "militaridade" [militarité], há a presença desses significados por meio do significante.

Nessa altura dos apontamentos teóricos a respeito do mito, é pelas mãos do dinamarquês Hjelmslev, que procede do Círculo Linguístico de Copenhague, que os estruturalistas devem 0 apontamento da diferença entre denotação e conotação, operador precioso porque mostra que o discurso pode despregar-se de seu próprio plano de significação e gerar outras significações. A denotação é o sentido comum do uso da palavra, enquanto que na conotação - estamos no campo do sentido figurado - difere daquele que lhe é próprio. Nessa arquitetura complexa da língua, é o resultado da relação de um plano de expressão e um plano de conteúdo, sendo esse resultado o responsável por gerar a significação. Ocorre que este primeiro sistema pode tornar-se o ponto de partida de um segundo sistema, em que a significação primeira torna-se a expressão de outro conteúdo, ambos os sistemas se imbricando para formar uma significação outra, que é, ao mesmo tempo, extensiva ao primeiro sistema e estranha a ele. (OC, II, p. 695). 


\section{0 corpus}

Feitas as devidas apresentações dos aparatos metodológicos de enfrentamento para análise, apresentamos o corpus. Serão analisadas quatro capas das revistas Men's Health e quatro da G Magazine, publicadas respectivamente nos meses de fevereiro, março, abril e maio de 2008. Nas primeiras linhas, estão as capas da Men's Health e abaixo se encontram as da revista G Magazine. Nas capas de revistas a serem analisadas, o signo está presente. Assim, se considerarmos essas capas das revistas que parecem querer nos comunicar algo, no limite, sobre os corpos masculinos como mito, então, estamos tratando de um sistema de signos que opera como significante para, logo em seguida, constituir outros novos signos. Como um sistema mítico, essas capas de revista buscam construir uma realidade e dar sentido a algo que parece desordenado e que soa um pouco caótico ao espírito.
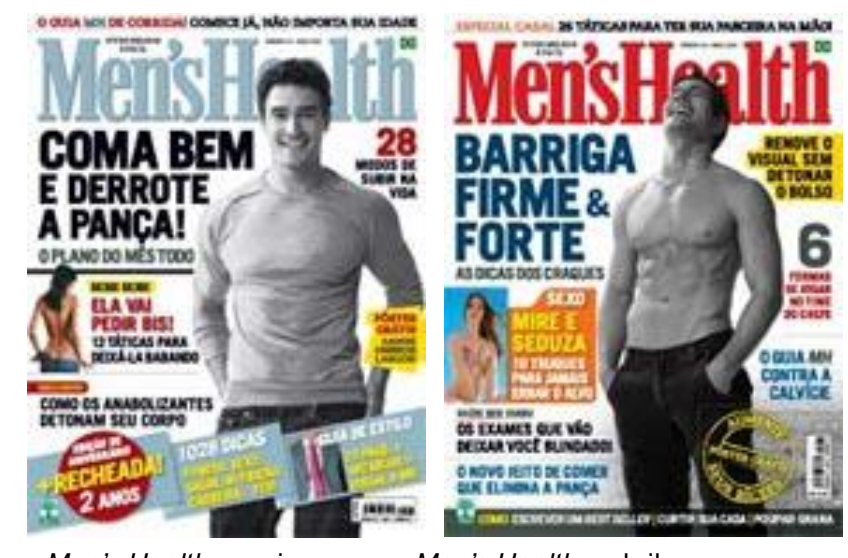

Men's Health - maio

Men's Health - abril

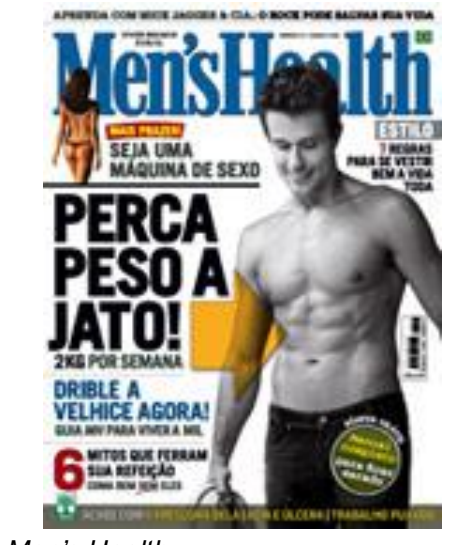

Men's Health - março
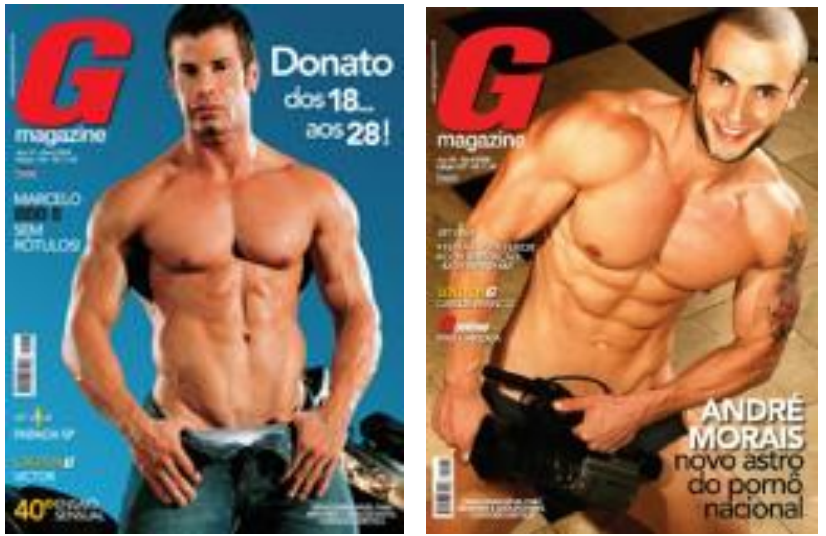

G Magazine-maio

G Magazine-abril

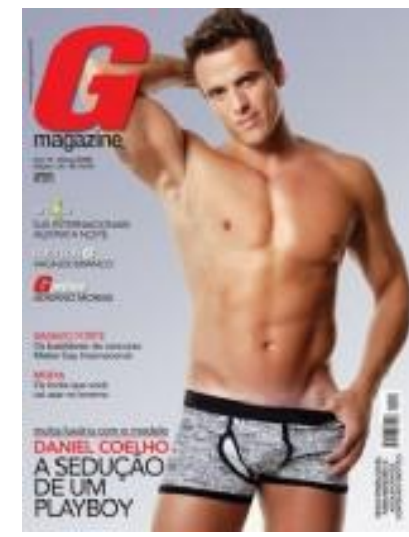

G Magazine - março

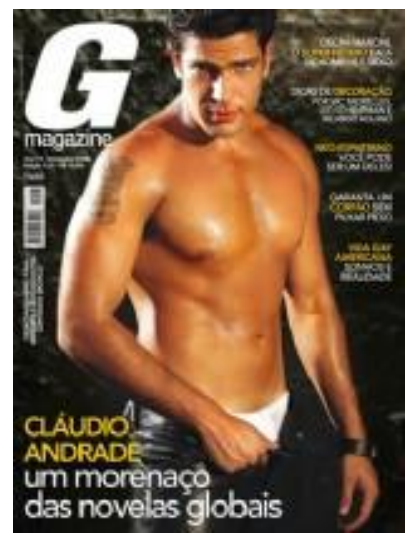

G Magazine - fevereiro

Que convite se pode depreender do plano imagético das revistas Men's Health e G Magazine quando, num primeiro golpe de olhar, o que se vê em ambas são, quase sempre, figurações de modelos masculinos representados em sua forma mais expressiva: com seus torsos nus, cujos músculos são evidentemente bem trabalhados e abdômen bastante "chapados"? O que se percebe, a partir dessas capas, é que, embora o corpo seja ainda o último reduto do erótico, a simples presença do torso nu não garante em si mesma um convite a sua experiência. É preciso que essa presença seja construída. E essa construção é bastante elaborada nas capas da $G$ Magazine.

Se, por um lado, ambas as capas de revistas se constituem da figuração, em primeiro plano, de corpos masculinos a torso nu, em Men'shealth, esse corpo é imageticamente destituído de sensualidade. A opacidade das imagens - propiciada pelo tom cinza, garantida pela predominância do preto e do branco e 
reforçada pela carga retórica dos títulos das matérias que "guarnecem" o corpo - ancora a leitura para uma vertente não exatamente do saudável, mas do binômio saúde-beleza, algo bem próximo do ideal narcisista de perfeição.

Um caminho para se conquistar o tal corpo definido e saudável é o que as capas de Men's Health oferecem ao leitor a cada mês. Os modelos masculinos de Men's Health não encara o leitor. Salvo na capa do mês de maio, em todas as outras, os modelos estão com os olhares desviados dos "olhos" da câmera. Isolados no retângulo cênico da capa, encenam a naturalidade das atividades praticadas no dia-a-dia. Ao desprezar o olhar do leitor e não dialogar diretamente com ele, chamam a atenção para os músculos definidos, para a ausência de gordura corporal, para a postura ereta e segura. A cor cinza da pele em contraste com o fundo branco de apagamento das referências espaciais e temporais, marca do mito - e o olhar que se desvia os despersonaliza. O mito, retirado de seu contexto original sofre um esvaziamento e, como significante, torna-se vazio. Todavia, quando atualizados pelo olhar do leitor, que os toma no contexto da capa e a partir do referencial que é o universo do culto ao corpo, tornam-se signos. Esse corpo acinzentado não é o corpo para o prazer de quem o observa, ele está ali como suporte para as projeções do observador que, ao se pôr em "em atividade", em marcha também poderá alcançar o corpo sem "pança", de "barriga firme \& forte" preconizado pelas manchetes de cada número da revista e seus pressupostos anunciantes. Um corpo saudável e, acima de tudo, belo em sua plena definição de músculos.

Ocupando dimensões cênicas parecidas, os corpos masculinos de G Magazine são postos sobre suas capas de maneira muito mais viva. O plano de fundo colorido, o tom bronzeado da pele, a exploração de luz e sombra, o olhar direto para o interlocutor conferem aos corpos desses modelos uma ilusão de realidade, de sensação e sentidos. Nas capas da G Magazine, tudo é cor, luminosidade, textura; há, no limite, até mesmo uma espécie de convite ao envolvimento tátil quanto à falsa ilusão de volume que o trabalho de sombra e luz fotográfica cria sobre a imagem. Um corpo que se oferece mais do que à contemplação do olhar do outro, dá-se à exploração tátil. Nesse simulacro que é o corpo, e o corpo no contexto da capa da revista G Magazine, investe-se todo um envolvimento imaginário entre o observador e o sujeito observado. O apelo aqui desliza do binômio saúde-beleza para outro ou outros como, por exemplo, saúde-potência, beleza-sexo. Da mesma forma, a ênfase dada ao torso - verificada nas capas das duas revistas -desliza, nesta última, para a região púbica. A pelve e a genitália são ressaltadas pelas mãos que insinuam abaixar a peça íntima ou pelos objetos cênicos, como a filmadora, que assumem a função de tapar a região pubiana e deixar a imaginação do leitor remontar o que está escondido. Obviamente, não é do falo em seu sentido poético e mítico que se está falando nessas capas, mas do pênis como objeto, de seu suposto tamanho e potência, os quais só serão verificados, em parte, ao folhear a revista depois de pagar por ela.

O texto verbal reforça 0 imaginário homoerotizante que a imagem em si mesma estimula e provoca. Se, por um lado, na Men's Health os modelos estão, em certa medida, em sua plena vitalidade física, por outro, os da G Magazine se apressam em fazer dessa mesma vitalidade em cena uma quase inércia total, a ação esperada é a do interlocutor, em essência, o leitor e comprador da revista. Sua apresentação lânguida (voluptuosa) e, outras vezes, reclinada em gestos bastante provocativos e eróticos - assim codificados pela cultura de massa, seus meios e veículos - é um convite a um jogo sensual tornado quase natural. $O$ olhar trocado com o observador de tais capas parece possível, esquece-se que a foto foi feita num estúdio, com luz, filtros, cenários escolhidos para criar tais efeitos e também que aquelas expressões fisionômicas e poses derivam do que a cultura, com toda sua coerção e poder coesivo, denotam como sensual, erótico, até mesmo venal e, ressalte-se aqui novamente, a passividade encenada simula o doar-se para o prazer que se dá numa relação de compra e venda, afinal, não se pode esquecer de que o 
exemplar da revista e todos os produtos ali anunciados não são gratuitos. Há aí um jogo contínuo de esvaziamento e recobrimento, o corpo, o sexo, o homem tornam-se objetos com valor de troca.

A imagem vê e é vista. O significante vazio encontra lastro nos conteúdos e jogos eróticos praticados pela cultura. Cultura essa que nos permite, por um lado, prever e construir uma significação a partir de signos partilhados por seus falantes e cujos valores se estabelecem em relação a outros signos nos dizeres de Saussure - e se fecham no contexto da capa da revista e, por outro, compreender cada um dos signos aí utilizados como parte de um mito no sentido barthesiano de mentira, simulacro - maior de desejo e realização carnal, de consumação do prazer sempre ofertado, mas nunca, de fato, realizado. Em última instância, no caso das duas revistas, o pênis não mostrado - pelo menos não na capa, no caso da G Magazine - é a mais potente das imagens.

Afinal, o que se quer com essas capas de revista? Percebamos que, embora a Men's Health e a G Magazine, nas edições analisadas, empreguem, igualmente, imagens de corpos masculinos que enfatizam o torso desnudo ou insinuado, a maneira como poeticamente são aí tratadas certas partes do corpo masculino, sua construção cênica, pode funcionar como ancoragem e suporte de diversas mensagens, como escreve Barthes em seu posfácio intitulado "O mito hoje": a função mesma do mito é a de "transformar o sentido em forma. Dito de outra maneira, o mito é sempre um roubo de linguagem" (OC, I, p. 843). Toma-se o torso masculino nu não para transformá-lo em exemplos, símbolos, mas para neutralizar, mesclar, por um lado, beleza com saúde, com se esta estivesse intrinsecamente associada àquela e, por outro, padronizar e reduzir 0 homoerotismo ao prazer que o falo pode proporcionar ao outro.

\section{Referências}

BARTHES, Roland. CEuvres Complètes. 5 T. Paris: Seuil, 2002.
. Aula. São Paulo: Cultrix, 1980.

Fontes, 2001.

1996.

. Elementos de semiologia. São Paulo: Cultrix,

. Mitologias. São Paulo: Difel, 2006.

CALVET, Louis-Jean. Roland Barthes: uma biografia. São Paulo: Siciliano, 1993.

DOSSE, François. Historia do estruturalismo. O canto dos signo. v.l. Bauru: EDUSC, 2007.

HJELMSLEV, Louis Trolle. Prolegômenos a uma teoria da linguagem. São Paulo: Perspectiva, 2006.

MOTTA, Leda Tenório da.Literatura e contracomunicação. São Paulo: Unimarco, 2003.

NÖTH, Winfried. A semiótica no século $X X$. São Paulo: Annablume, 2005.

PERRONE-MOISÉS, Leyla . Roland Barthes e o prazer da palavra. Revista Cult. Edição 100, março 2006.

Revista G Magazine. G Online. Disponível em: < http://gonline.uol.com.br/site/arquivos

/estatico/gmagazine.htm >. Editor responsável: Marcos Brandão. Acessado em 10 de julho de 2008.

Revista Men's Health. Disponível em: < http:// menshealth.abril.com.br/home/index.shtml >. Editor responsável: Airton Seligman. Acessado em 08 de julho de 2008. 